\title{
Etnografiando la bolsa de valores: São Paulo, 1993
}

\author{
Fernando Rabossi
}

\section{Lúcia Helena Alves Müller, 2006}

Mercado Exemplar: um estudo antropológico sobre a Bolsa de Valores

Zouk, Porto Alegre, 173 pp.

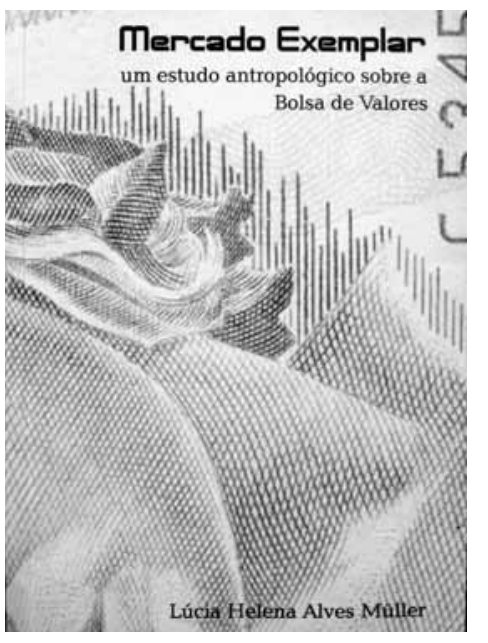

$M$ Tercado Exemplar..., escrito por Lúcia Helena Alves Müller, es un estudio antropológico sobre la Bolsa de Valores de São Paulo (Bovespa), Brasil. El libro es una revisión de la tesis de doctorado de la autora, realizada en el Departamento de Antropología de la Universidad Nacional de Brasilia y defendida en 1997. Después de 15 años sigue siendo la única tesis de doctorado en antropología sobre la Bolsa de

\section{Doing Ethnography of the Stock Market: São Paulo, 1993}

Fernando Rabossi: Universidad Federal de Río de Janeiro, Río de Janeiro, Brasil

rabossi@rocketmail.com
Valores escrita en Brasil. ${ }^{1}$

Basado en un trabajo de campo desarrollado en 1993, el libro analiza el funcionamiento de la Bolsa de Valores de São Paulo a partir de los actores que participan en ella, las relaciones que mantienen entre ellos, las lógicas subyacentes a sus prácticas y los códigos e identidades que se articulan en dicho lugar. El pregón a viva voz - o rueda de piso, como también es conocido en español- es el foco principal con base en el cual son explorados todos esos elementos.

\footnotetext{
${ }^{1}$ Existen tesis defendidas en las áreas de administración, contabilidad, ingeniería de la producción, derecho e historia. Para consultar las tesis de maestría y doctorado producidas en Brasil, véase <http://capesdw. capes.gov.br/capesdw/>.
} 
Como una de las instituciones primordiales del sistema capitalista - en términos tanto económicos como simbólicos-, el funcionamiento de la Bolsa de Valores condensa los principios rectores de dicho sistema: atomicidad, competencia, transparencia y libertad de elección. Esos principios, sin embargo, no siempre operan como establecidos en los términos ideales del modelo de mercado. ¿Cómo explicar esta discrepancia? ¿Es el modelo una ficción? ¿Es en realidad la Bolsa de Valores un nido de corrupción? La respuesta de Müller trasciende esas explicaciones reduccionistas y muestra qué tanto el modelo y las prácticas que lo contradicen son fundamentales para entender su funcionamiento. El modelo es esencial, pues funciona como un ideal regulador que estructura institucionalmente la dinámica bursátil, por ejemplo a través de mecanismos que posibilitan la competencia, la circulación de información, la ecuanimidad o la conexión del mercado de acciones con la dinámica productiva. Como ideal regulador, nada tiene de natural, sino que depende de la implementación de reglas que garanticen su funcionamiento, algo que aparece descrito con precisión en el capítulo 2, "El libre mercado". Como la autora lo expresa: "Definitivamente, el mercado no es el espacio del vale-todo. Por el contrario, como fue demostrado, muchas normas $\mathrm{y}$ controles son necesarios para que en las bolsas imperen las condiciones preconizadas por el modelo ideal del mercado perfecto" (p. 34). ${ }^{2}$

Las dinámicas que contradicen el modelo ideal de mercado, por otro lado, son indispensables para el funcionamiento real de la Bolsa. Tal vez el ejemplo más claro a este respecto sean las relaciones de confianza y las redes de relaciones que operan en la Bolsa, analizadas en el capítulo 4, “¿Negocios aparte?”. Entre la competencia - la imagen de cómo deberían funcionar las relaciones entre los actoresy la corrupción - la imagen de las relaciones después de descubrir que no funcionan exclusivamente bajo el imperativo de la competencia-, Alves Müller identifica la existencia de amplias redes de reciprocidad que conforman "un sistema de intercambios interesados y que tienen por objeto informaciones, indicaciones, privilegios $\mathrm{y}$, como objetivo, el establecimiento de lazos y compromisos de largo plazo" (p. 64). La centralidad y la normalidad que tienen esas redes en el funcionamiento de la Bolsa quedan en evidencia al observar que participar en amplias redes de relaciones es, de hecho, "el gran patrimonio que

\footnotetext{
2 Todas las citas del texto son una traducción libre del original en portugués.
}

un profesional puede construir a lo largo de su carrera" (p. 69).

En la definición de la autora, la Bolsa de Valores se entiende "no como la práctica imperfecta de un modelo abstracto, sino como una institución social cuya legitimidad se asienta en este modelo ideal, en cuyo interior conviven y compiten entre sí diversos órdenes" (p. 156). La descripción etnográfica de éstos y su combinación con el análisis fino del modelo y su interrelación con las prácticas cotidianas es lo que da al libro su riqueza y utilidad para comprender esa "institución ejemplar" que es la Bolsa de Valores, la cual constituye una ventana privilegiada para entender la dimensión simbólica de las relaciones de mercado en nuestras sociedades.

El capítulo 1, "Mercado ejemplar", presenta las elecciones teóricas que llevaron a la autora a estudiar la Bolsa de Valores de la manera hasta aquí descrita: por un lado, el entendimiento del mercado como modelo cultural, en el sentido geertziano del término, a partir de una genealogía que pasa por Marx, Weber, Polanyi, Dumont y Sahlins; por otro lado, el entendimiento del mercado como institución social caracterizada por la heterogeneidad de referencias sociales, económicas y simbólicas presentes en su interior. Aquí la autora utiliza los diferentes "órdenes de grandeza" 
_ "mundos" o "cites" - descritos y sistematizados por Luc Boltanski y Laurent Thévenot en De la Justification. Les Économies de la Grandeur (1991).

En el capítulo 2, como dijimos, se describe el funcionamiento del pregón a viva voz. Se muestra no sólo el espacio donde ocurren las transacciones y cómo son vendidas y compradas las acciones, sino también las reglas que lo regulan. Dos contrastes esenciales para comprender el funcionamiento de la Bolsa y las transformaciones que se consolidarán a lo largo de la primera década del siglo xxI con la negociación de acciones a viva voz son expuestos por Alves Müller: las negociaciones con productos derivados - como opciones y futuros- y el denominado "pregón electrónico" - transacciones operadas vía computadora-.

De hecho, el pregón a viva voz descrito por Alves Müller no existe más en la Bovespa, fue reemplazado por el sistema de pregón electrónico en 2005. En este sentido, el libro tiene el valor de ser el registro de un momento específico en la historia de las Bolsas de Valores, el cual se ve enriquecido por la atención que la autora presta al proceso de transformación que estaba observando. El sistema de negociaciones electrónico en la Bovespa fue implantado en 1982, por lo que la autora analiza la forma en que las reglas que imperan en el pregón a viva voz fueron adaptadas a las innovaciones tecnológicas.

En el capítulo "Los que mueven el dinero" la autora presenta a los actores que participan en la Bolsa. La primera cuestión a destacar es la importancia fundamental de las instituciones financieras en su funcionamiento -en 1994 eran responsables de $82.1 \%$ de todo el dinero aplicado-. Las instituciones financieras son casas de bolsa, bancos, fundaciones, fondos de pensión, compañías de seguros y empresas. En el caso brasileño, esa pluralidad de instituciones es relativamente reciente. $\mathrm{La}$ Bovespa fue fundada en 1890 . Hasta 1966 existía un número limitado de casas de bolsa oficiales, que funcionaban como las intermediarias exclusivas entre los inversores y la Bolsa, con la particularidad de ser concesiones hereditarias que pasaban de padre a hijo. A partir de ese año, las casas oficiales dieron lugar a las casas de bolsa - corretoras de valores, en portugués-y en 1988, gracias a una nueva legislación, muchas de las instituciones financieras se transformaron en bancos.

Esta historia permite hacer una primera distinción entre las casas tradicionales ligadas a las familias fundadoras y las vinculadas a grandes grupos financieros. Si las grandes instituciones financieras tienen un sesgo más corporativo, reclutan operadores con un perfil profesional más establecido, las casas de bolsa son más abiertas a los desempeños individuales, lo que explica que $80 \%$ de los directores de casas corredoras de valores o de mesas de operación iniciaran sus carreras como office boys. Claro que la posibilidad de ascender depende de la coyuntura del mercado y en contextos favorables el número de operadores puede duplicarse, lo que multiplica las oportunidades de aquellos que participan.

Si el capítulo 4, “¿Negocios aparte?", es un análisis detallado de las relaciones que establecen entre sí los participantes de la Bolsa, el capítulo 5, "Homo economicus", analiza las lógicas subyacentes a sus acciones: la racionalidad económica, la especulación y el juego. La imagen de individuo presente en el modelo teórico del mercado perfecto corresponde a la de actores racionales que maximizan sus objetivos. Ese modelo se adecua a los llamados "inversores conservadores", los cuales conciben sus aplicaciones en la Bolsa como inversiones que rendirán los dividendos decurrentes de los lucros de las empresas de acuerdo con su desempeño real. El secreto aquí es saber el valor de las acciones en relación con el desempeño de las empresas, i. e. el "precio técnico" de las acciones. Para eso, una serie de técnicas son utilizadas - los "análisis 
fundamentalistas" - por los profesionales encargados de administrar estas inversiones. Como las instituciones financieras están obligadas por ley a invertir $25 \%$ de su patrimonio líquido en el mercado bursátil, gran parte de los inversores conservadores son instituciones financieras.

Aquellos que prefieren obtener lucro a partir de las variaciones de precios derivadas de la oferta y la demanda de acciones en la Bolsa son llamados “especuladores". La especulación opera en una escala temporal diferente a la de las inversiones conservadoras, puesto que el riesgo asumido por el inversor, en vez de estar ligado al

en su área de actuación, está vinculado al de las acciones de la empresa en las oscilaciones cotidianas de sus precios. $\mathrm{La}$ lógica es simple en apariencia, como uno de los operadores le dijera a la autora: "No hay error: comprar cuando baja y vender cuando sube" (p. 88). La cuestión es saber cuándo comprar y cuándo vender. Para eso se utilizan los "análisis grafistas", un tipo de técnica que procura prever la tendencia de las acciones en el corto plazo. A diferencia de los profesionales que administran conservadoramente las inversiones de sus clientes, en general asalariados, quienes se dedican a especular con las

inversiones de sus clientes suelen trabajar por comisión o como autónomos vinculados a una casa de bolsa específica.

La tercera lógica apuntada por la autora sería la del juego, que operaría también en la oscilación de precios en el mercado de acciones en situaciones $o$ momentos en los que la imprevisibilidad es la característica determinante del mercado. A pesar de ser descrita como otra lógica, el juego se despliega en diversas dimensiones a lo largo del capítulo. Por un lado, como una categoría que describe a algunos actores específicos -los “jugadores"-, que serían inversores individuales que administran sus negocios personalmente, a pesar de necesitar de una casa de bolsa para poder procesar sus inversiones. Por otro lado, como dimensión explicativa que permite dar testimonio de éxitos o fracasos - por la suerte o el destino- y que fomenta otras técnicas de control, como la adivinación o pequeños rituales cabalísticos (p. 103). Dada la imprevisibilidad de las negociaciones de productos derivados, de acuerdo con la autora los mercados de opciones $\mathrm{y}$ futuros aparecen como regidos por la lógica del juego - o por la lógica de la manipulación de inversores privilegiados-.

El capítulo 6, "Especulando con la información”, aborda el papel de la información en el mercado bursátil. Aquí, otra vez, la distancia entre los presupuestos del modelo ideal de mercado - la transparencia de la información objetiva y disponible para todos- $-y$ las diferentes formas de acceso, producción y manipulación de información revelan la centralidad que tiene ese principio en la estructuración y legitimación del mercado, a la vez que descubre uno de los principales elementos sobre los cuales se compite. En palabras de Müller, "es alrededor del acceso a la información que sucede, por tanto, la verdadera competencia entre los participantes en el mercado" (p. 126).

En el último capítulo, "El precio justo", la autora examina tres concepciones predominantes en el mundo de la Bolsa a partir del análisis de tres personajes. El primero es un gerente de inversiones cuyo caso remite al mundo de la economía real, aquello que Boltanski y Thévenot llaman "mundo industrial", dominado por los principios de la razón instrumental. El segundo es un operador independiente cuyo caso alude al mundo de la especulación, el "mundo mercantil” de Boltanski y Thévenot, pautado por la lógica de la competencia. Por último, el caso de la inversora individual se refiere al mundo del juego, el "mundo inspirado" para estos autores, el mundo de valores trascendentes que permiten dar 
sentido al carácter aleatorio de los resultados. El capítulo es un intento de articular, a través de trayectorias particulares, diferentes formas de concebir y vivir el mercado, que muestra la compleja articulación entre determinaciones y posibilidades abiertas a los actores que participan en la Bolsa de Valores. Estas articulaciones tienen por límite el modelo ideal que aparece de manera recurrente a lo largo del texto y sobre el cual se asienta su legitimidad frente a la sociedad. La legitimidad de la Bolsa frente a la sociedad se basa en la presentación de sí misma como instrumento de promoción de inversiones en la actividad productiva, a través de los principios de mercado. Además de las normas formales que sostienen esa construcción, otros principios operan con el mismo objetivo.

Como la autora manifiesta:

el mercado no funcionaría si sus participantes no constituyeran una comunidad que comparte mínimamente los mismos valores y el mismo código de conducta. Más allá de todas las normas y de los controles legales, la vigencia de estos códigos informales es fundamental para la regulación de las relaciones entre los participantes del mercado y la exclusión de esa comunidad de relaciones recíprocas es la más grave sanción que pueden recibir aquellos que no los respetan (p. 158).
Si la legitimidad de la Bolsa está basada en su conexión con la actividad productiva, la importancia que pasan a tener productos como opciones y futuros presenta una desconexión más radical de esos universos, al invertir, según Müller, el sentido de la conexión entre esos mercados. Las opciones y los títulos futuros, de ser instrumentos para garantizar la seguridad de los inversores frente a la volatilidad de los mercados, adquieren el efecto contrario: "haciendo que las cotizaciones de las acciones en la bolsa dejen de ser definidas por la oferta y la demanda de las mismas y se transformen en meros efectos de los intereses de aquellos que aplicaron dinero en sus derivativos" (p. 93). El lugar de los mercados de productos derivados y los desafíos que interponen al funcionamiento de la Bolsa - en especial en lo que respecta a los principios de legitimación de la misma- es uno de los elementos que el trabajo de Müller nos ayuda a pensar. Máxime si consideramos en particular que en 2008 la Bolsa de Valores de São Paulo y la Bolsa de Mercaderías y Futuros se fundieron para formar la Bolsa de Valores, Mercaderías y Futuros de São Paulo (BM\&FBOVESPA, S. A.), lo que indicó un camino específico para los mercados financieros.

No cabe duda de que la riqueza de este libro trasciende el carácter resumido de esta reseña.

Principalmente, por constituir un retrato etnográfico de un universo poco estudiado, por lo menos para la época en que la investigación fue realizada. Junto al trabajo de campo de Ellen Hertz (1998) sobre la Bolsa de Valores de Shanghai, más o menos de la misma época, este libro es una de las primeras etnografías producidas desde la antropología sobre Bolsas de Valores. Por este motivo, por la sutileza de la discusión y por el cuidado con que está escrito, valdría la pena que circulara fuera de las fronteras brasileñas.

\section{BIBLIOGRAFÍA}

Boltanski, Luc y Laurent Thévenot, 1991, De la Justification. Les Économies de la Grandeur, Gallimard, París.

Hertz, Ellen, 1998, The Trading Crowd: An Ethnography of the Shanghai Stock Market, Cambridge University Press, Cambridge.

Müller, Lúcia Helena Alves, 2006, Mercado Exemplar: um estudo antropológico sobre a Bolsa de Valores, Zouk, Porto Alegre. 